\title{
Undergraduate optical engineering at the University of Arizona
}

Jack Gaskill, James Palmer, Michael Nofziger

Jack D. Gaskill, James M. Palmer, Michael J. Nofziger, "Undergraduate optical engineering at the University of Arizona," Proc. SPIE 2525, 1995 International Conference on Education in Optics, (13 October 1995); doi: $10.1117 / 12.224079$

SPIE Event: SPIE's 1995 International Symposium on Optical Science, Engineering, and Instrumentation, 1995, San Diego, CA, United States 
Undergraduate optical engineering at The University of Arizona

Jack D. Gaskill

The University of Arizona, Optical Sciences Center

and Department of Electrical and Computer Engineering

Tucson, Arizona 85721

James E. Palmer and Michael J. Nofziger

The University of Arizona, Optical Science Center

Tucson, Arizona 85721

\begin{abstract}
Planning for the undergraduate Optical Engineering program at the University of Arizona, which leads to the B.S. Degree in Optical Engineering, was begun in the mid 1980's -- primarily in response to a cry from industry that there was a national shortage of individuals with formal training in optics at the baccalaureate level. The curriculum for the new degree was modeled after that of the Institute of Optics at the University of Rochester to some extent, but was given somewhat more more of an electrical engineering flavor. In addition to the usual doses of mathematics, chemistry, physics and social sciences found in standard engineering programs, the University of Arizona program requires 22 units (semester credit hours) of electrical engineering, 30 units of optical engineering and 12 units of senior-level technical electives, for a total of 128 units. The program has grown at a moderate rate since it was given official status in 1989, and 72 students were enrolled as Optical Engineering majors during the spring semester 1995; the maximum enrollment of 100 will be likely be reached sometime before the year 2000. A total of 35 individuals have now received the B.S. Degree in Optical Engineering at the University of Arizona. The philosophy and curriculum of this program is described in some detail.
\end{abstract}

Keywords: optics education, undergraduate optics education, optical engineering education

\title{
1. INTRODUCTION
}

We (the authors) were flattered, but puzzled, by a recent request that we present a paper at SPIE's 1995 International Conference on Education in Optics entitled "Undergraduate optics education at the other place". We declined, of course, because we did not believe we were familiar enough with the University of Rochester's program to write about it with authority. However, we did agree to present a paper about undergraduate optics education at "the place".

Efforts to establish this program, which leads to the B.S. Degree in Optical Engineering, began at the University of Arizona in the mid eighties -- primarily in response to a plea from industry that there was a national shortage of individuals with formal training in optics at the baccalaureate level. One of us (Gaskill) ended up leading the charge because, as Associate Director of the Optical Sciences Center and administrator of the Optical Sciences Industrial Affiliates Program, he had grown weary of being beaten about the head and shoulders by our industrial friends regarding the aforementioned shortage of optical engineers. In addition, there was a strongly held belief by many of our colleagues that such a program would be beneficial for both the nation and the State of Arizona.

We point out, however, that not all members of the Optical Sciences faculty were in favor of the program, nor were all members of the University administration. Opponents argued that the degree would be too specialized, that graduates of the program would be ill-prepared for graduate school, that graduates would not be able to find jobs, that the cost of the program was too high, etc. Nevertheless, after an intensive educational effort, protracted debates and endless discussions, proponents of the program finally prevailed and its establishment was approved by both the Optical Sciences faculty and the University administration. Subsequently, our request for the authorization of, and funding for, a program leading to the B.S. Degree in Optical Engineering was approved by both the Arizona Board of Regents and the Arizona Legislature.

At that point it appeared that the final obstacle had been overcome. Not so! Unlike the Institute of Optics (the other place), the Optical Sciences Center is not formally in a "college" and, therefore, did not fit the definition of an "undergraduate academic unit." As a result, there was considerable administrative discomfort associated with allowing this newly authorized 
program to be administered by the Optical Sciences Center, and we were instructed to find a "proper" home for the program. After a period of additional discussions and negotiations, the Department of Electrical and Computer Engineering agreed to serve as the home department for the new program, and that is where it now resides. Consequently, there are presently three undergraduate degrees administered by the Department of ECE: the B.S. Degree in Electrical Engineering, the B.S. Degree in Computer Engineering and, now, the B.S. Degree in Optical Engineering. To assist in the administrative activities, several members of the Optical Sciences faculty were given joint appointments in ECE, and vice versa.

\section{CURRICULUM}

The curriculum for the new degree was modeled after that of the Institute of Optics to some extent, but was intentionally given somewhat more of an electrical engineering flavor. In addition to the usual mathematics, chemistry, physics and social sciences found in standard engineering programs, the University of Arizona program requires 22 units (semester credit hours) of electrical engineering, 30 units of optical engineering and 12 units of senior-level technical electives, for a total of 128 units. Of the required units of optical engineering, 8 are earned in superb, hands-on laboratory courses, the equipment for which was purchased primarily with funds provided by Industrial Affiliates of the Optical Sciences Center. The subjects of the electrical-and optical-engineering courses are described briefly below.

\section{Electrical Engineering Courses::}

ECE 220. Basic Circuits. Sinusoidal and transient analysis of elementary linear circuits, with laboratory.

ECE 274. Digital Logic. Number systems; coding; digital logic; sequential systems; register transfer language.

ECE 275. Computer Programming. Fundamentals of C; numerical precision; engr. problem solving; etc.

ECE 320. Circuit Theory. The frequency domain; poles and zeros; two-port network parameters; etc.

ECE 351a. Electronic Circuits. Operational amplifiers; diode circuits; MOS transistors; digital circuits; etc.

ECE 352. Device Electronics. Electronic properties of semiconductors; carrier transport; $\mathrm{P}-\mathrm{N}$ junctions; etc.

ECE 381. Electromagnetics. E\&M fields; Maxwell's equations; planes waves; transmission lines; etc.

Optical Engineering Courses::

OPTI 210. Geometrical Optics. Principles of light; reflection; refraction; paraxial optics; aberrations; etc.

OPTI 210L. Geometrical Optics Lab. Laboratory associated with OPTI 210.

OPTI 226. Physical Optics. Electromagnetic waves; plane harmonic waves; interference; diffraction; etc.

OPTI 226L. Physical Optics Lab. Laboratory associated with OPTI 226.

OPTI 342. Optical Systems Analysis. Applications of Fourier methods in diffraction and image formation; etc.

OPTI 350. $\quad$ Radiometry, Sources and Detectors. Radiation transfer; blackbody radiation; measurements; etc.

OPTI 370. Lasers and E-O Devices. Solid-state physics; laser physics; beam manipulation; modulators; etc.

OPTI 412. Optical Instrumentation. Microscopes; telescopes; cameras; ophthalmic instr.; optical scanners; etc.

OPTI 416. Optical Design, Fab. and Test. Design; fabrication; testing; lens mounting and centering; etc.

OPTI 470a. Optics Laboratory. Advanced geometrical optics laboratory.

OPTI 470b. Optics Laboratory. Advanced physical optics laboratory. 


\section{PROGRAM EVOLUTION AND OUTLOOK}

The B.S. Program in Optical Engineering at The University of Arizona has grown at a moderate rate since it officially began in 1989, and 72 students were enrolled as Optical Engineering majors during the spring semester 1995. We anticipate that the maximum authorized enrollment of 100 that will be reached sometime before the year 2000 .

In commenting on the employment opportunities that graduates of this program will have in the years to come, we realize, of course, that there are hazards associated with predicting the future. Nevertheless, we make the following predictions with the exuberant confidence and total conviction of a government economist (although, as the saying goes, if all the economists of the world were laid end to end, it would probably be a good idea). To begin with, it should be mentioned that there are currently fewer than 100 baccalaureate degrees awarded in optics or optical engineering in the United States each year, and that this situation will surely continue even after the program at the University of Arizona reaches its maximum enrollment. Consequently, although the current employment opportunities for graduates are not nearly as good today as they were just a few short years ago, it is our opinion that the relative demand for such individuals is presently greater than for those of most other engineering disciplines. As for future employment opportunities, we believe that technological advances and an improving global economy will result in an increased need for optical engineering graduates within two or three years, and that this increased demand will exceed the supply for many years.

It is interesting to note that, of a total of 35 individuals who have now received the B.S. Degree in Optical Engineering at the University of Arizona since the first class graduated in May 1992, approximately one third are currently employed in their chosen career field. It is also interesting to note that, in spite of the belief stated by some of our faculty that graduates of this program would not be well prepared for graduate school, approximately one third of these graduates will be attending graduate school in the fall of 1995.

\section{ACKNOWLEDGEMENT}

We would like to thank the many dedicated members of the staff and faculty of the Optical Sciences Center and the Department of Electrical and Computer Engineering who help make this program successful, and we would also like to thank the Optical Sciences Industrial Affiliates who have contributed significant amounts of money and equipment to the program. 